sisted in a feeling as if he rested on the back of his head, left nates, and heel, I raised the stretcher and replaced the top mattress by one having a round hole ten inches in diameter cut in its centre. The stretcher being replaced and the centre strip of canvas loosened, his nates

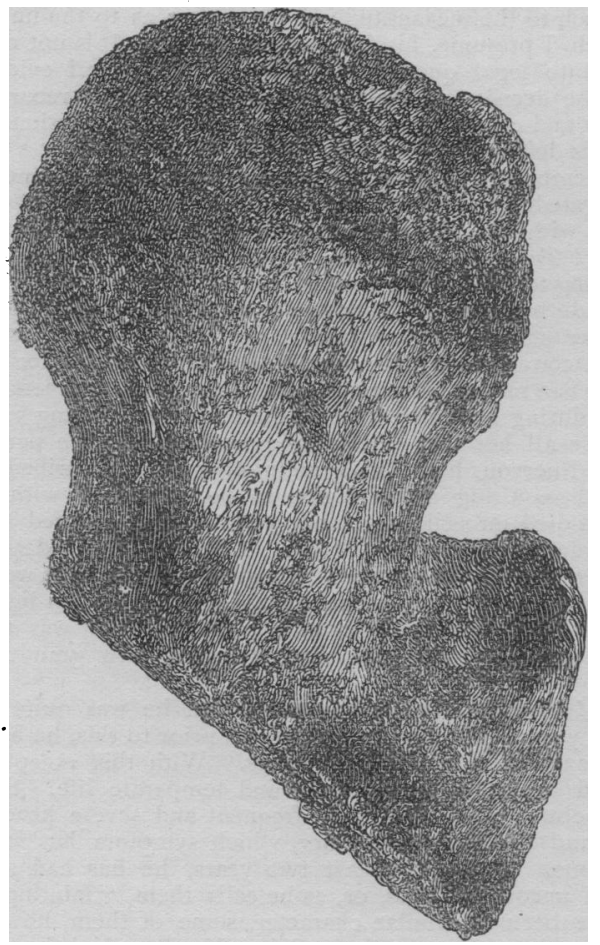

Fig. 4.

fitted into this hole, which removed all pressure from his sacrum, on which a large bedsore had formed during the two days of his great prostration. The comfort of this arrangement was indescribable; but then came the question of extension of the limb; this I effected by a four-pound weight attached to the foot and suspended over a pulley adapted to an upright fixed in the floor at the bottom of the bed. The limb was supported by sand-bags, and the nates fitting into the hole in the mattress formed, as it were, the point for counterextension.

From this time forward, he steadily improved. By means of the stretcher, he was raised from the bed, the wound dressed as well as the bedsore, sheets rearranged, the necessary utensils made use of, mattresses removed and aired, and his position in the hospital or his room altered.

On May Ist, extension was discontinued and the limb simply supported by sand-bags. On the 21 st, he was able to move the limb slightly. On July Ioth, the stretcher was shifted from under him for the first time, and, with a little help, he turned both legs out of bed. On the 26 th, he commenced to walk with crutches, in which he daily improved. The great cavity left by the wound of operation steadily healed from the bottom, being simply dressed with carbolised oil morning and evening.

His convalescence was materially retarded by the old wound from the necrosis of the femur reopening, apparently in consequence of a piece of bone being set free.

The limb (ten months after the operation) is about two inches shorter than the sound one; but this great difference is in some measure due to the knee being still slightly flexed. There is no pain in or about the seat of operation. When he stands erect, he can lateralise and rotate the limb for several inches; and, with the aid of crutches, he can walk up and down stairs.

During the course of treatment, he complained of severe pain in the inside of the knee, which was invariably relieved when extension was being applied by taking care that it was in the axis of the leg, and not forcing the knee towards a straight position.

\section{NOTE ON GOUT.}

By G. OWEN REES, M.D., F.R.C.P., F.R.S., Consulting-Physician to Guy's Hospital.

NotwithstaNDING all that has been written and said concerning gout, we still find our knowledge of its pathology most uncertain, and the views of our modern authors differing in a remarkable manner. Having lately perused a valuable lecture by Sir James Paget on what he terms gouty phlebitis, I have been reminded of many facts and views observed and considered by me for years past, and these have proved of more interest since reading that lecture, and I have become the more inclined to entertain the belief that the phenomena of the acute gouty paroxysm are best explained on the theory that the disease is essentially a capillary phlebitis, the venous inflammation being caused by the circulation of a blood-poison.

The comments made by our best known authors on gout, when alluding to the works of their brother-labourers, show that serious objections exist against the reception of any theory yet propounded in explanation of the acute attack. Thus, while Dr. Garrod believes that the presence of uric acid in the blood constitutes gout, and that the effusion of urate of soda is the proximate cause of the fit, we find, on the other hand, that Dr. Gairdner gives reasons for altogether doubting the correctness of that view, stating that Dr. Garrod's theory "not only does not explain the symptoms, but is absolutely contradicted by them".

When considering the opposing opinions of authors, it has often struck me that there must be some condition necessary to the production of gout other than the presence of urinary constituents in the blood, while it must still be admitted that such contamination plays a considerable part in the causation of the disease. We cannot doubt that, before an attack of gout occurs, the blood always contains an excess of uric acid. This, Dr. Garrod maintains, produces the attack by depositing as urate of soda in the tissues. Dr. Gairdner argues that, if it be so, the inflammatory symptoms ought only to set in when the effusion of material takes place, whereas the severe pain and vascular excitement appear before the swelling takes place and subside immediately on its appearing.

These litigants, however, cannot but agree upon one point ; viz., that there is an excess of uric acid in the blood, though they differ so materially in regard to the effects attributable to its presence.

Now, we know that animal poisons of obscure character are occasionally produced in the blood, and cause inflammation of the veins among other evils. Is it not probable that, in gout, the blood, charged with urinary material, becomes so changed, that a poison is elaborated which inflames the venous capillaries? Sir James Paget has shown that the larger venous trunks are especially prone to disease in gouty persons. If so with the larger trunks, why not so with the capillaries?

The phenomena of the gouty seizure may, I think, be more satisfactorily explained on this theory than upon any other. The disease thus beginning in the elaboration of a poison from the urinary materials found in the blood, the venous capillaries inflame as a consequence; severe pain is experienced, which is relieved immediately when effusion and swelling occur.

Dr. Gairdner's views have especial reference to the veins, but he does not believe in any poisonous influence nor in the phlebitic state. He considers, however, that the "real seat and cause of the painful phenomena of gout" is in the distended venous capillaries, and he accounts for this distension as follows. "This fluid (the venous blood) is compressed between two opposing forces, that, namely, which is derived from the heart and arterial system, urging it forward on its course, and, on the other hand, the antagonistic resistance of the great veins leading to the right auricle." This position is attacked by Dr. Garrod, who states that the general state of vascular plethcra is by no means always present, and its absence is observed in spare sub. jects and in those who strongly inherit the disease. This objection seems well founded.

If we assume, however, that venous inflammation is present, then, of course, we can explain the condition of the larger veins of the limb, which, thus affected by poison, will not be able to propel the venous current, and will become distended and remain so till the poison is eliminated or destroyed.

It seems certain that, when urinary matters are retained in the blood, very different poisons may be formed, owing to some varying causes of which we know but little. Thus, in Bright's disease, the blood becomes so contaminated, but the effects, as is well known, are very different from those of the gouty seizure. The poison produced is of quite a different kind, its most distinctive character being shown in its powerful action on the brain and in the production of convulsive action. 
It is, of course, impossible to say how or why it is that the same urinary matters should become converted into different poisons in the blood in different diatheses; but, if we turn to non-vital chemistry, we find analogical results. The ferment present may differ, the fluids may vary in density or in temperature, and, in the one case, a poison may be produced capable of causing violent convulsion, and, in the other, a milder toxic agent may appear as a result, causing inflammation of venous capillaries and all the phenomena of acute gout.

In connection with this subject, I would wish to direct attention to the fact that a condition may be brought about by the gouty poison, which it is difficult to separate from ordinary pyæmia. I lately met with such a case in the person of a gentleman engaged in large practice, whose diathesis was decidedly gouty. The disease seized him in nearly every joint, and was treated at the onset with the ordinary approved remedies. After a few days had elapsed, he became anxious, and I was called to see him. I found both hands and feet swollen and tender. One knee was involved, and he complained a good deal of the back of his neck. His pulse was extremely weak, and so rapid that I counted it with difficulty. Notwithstanding this state of the circulation, his intellect was quite clear, but his respiration was rapid and his temperature IO4 deg. My first idea was that the case was one of ordinary pyæmia ; but from the history there could be little doubt that the disease commenced as gout. This gentleman recovered well under the free use of stimulants. During the progress of the case, there was a good deal of tenderness for two or three days over the saphena major vein, but the vessel did not become hardened or thickened. A pain occurred also over the hip during convalescence, and there was considerable tenderness over the part for a day or two. If the view I have here taken of the nature of gout be correct, it would appear that in treatment our object should be to exhibit some remedy capable of acting upon the poison and destroying its virulence. The power which colchicum evinces looks much like this, acting, as it often does, so very rapidly in removing gouty inflammation.

There are one or two points having reference to the treatment of this disease upon which I will venture to remark.

I. Too little attention seems to have been paid to the amount of solid food allowed to gouty patients. Most of them eat too much.

2. It is much the fashion to prescribe strongly alkaline waters in large quantity. This depresses the gouty, and tends to impair the digestive power of the stomach. In moderation, however, the milder alkaline waters are of value.

3. Though it is true in the general that alcoholic drinks in the form of spirits are better than wines, yet it often happens that these, after a time, become very objectionable to the patient, and prevent him eating his food with appetite. In this case, it is always better to allow wine, which should be always of the highest quality. From what I have observed, I am much inclined to believe that really good wines are generally used to advantage, and that the vegetable extractives of these mellowed specimens are easily digestible by the gouty stomach.

4. Much may be done by remedy to ward off the gouty seizure, and the patient generally receives a warning. When such symptoms arise, a combination of quina, colchicum, and colocynth, taken twice or three times a day, is an excellent medicine.

Some few years ago, I saw two gouty cases which much impressed me, and which showed how dangerous it is for gouty people to take quantities of cold water day by day, even though the quality of the fluid be of mild character. During a stay at Homburg, I was entreated to see an Englishman who was said to be in imminent peril. I found an inveterately gouty man with an immensely distended abdomen. The heart's action was thereby much impeded, and he was nearly pulseless. This was brought about by taking the waters in accordance with the generally prescribed rules. I saw a very similar case shortly afterwards. The treatment consisted in prescribing an opiate at night (for there had been great loss of sleep in both cases), and in administering alcoholic stimulus in the form of warm brandy and water. The patients recovered rapidly,

\section{THE MEDICAL FACTS AND EVIDENCE IN THE CASE OF THE QUEEN $v$. TREADAWAY.}

\section{By A. HUGHES BENNETT, M.D., M.R.C.P.}

ON February 8 th, 1877 , at the Old Bailey, Frederick Treadaway was sentericed to execution for the wilful murder of John Collins, and was also found guilty of an attempt to take the life of Mrs. Collins. As the defence was in great part of a medical character, and the case a very peculiar one, it may be interesting to the profession to learn the medical facts of the trial. This appears to be all the more necessary as the reports of the evidence as given in the daily newspapers were very imperfect and inaccurate, and, in some of the leading articles, even strictures were passed on the nature of the defence. Lastly, in the BRITISH MEDICAL JOURNAL of February 17 th, there is a letter criticising the medical evidence. This contains certain inaccuracies, and the conclusions are sometimes arrived at from erroneous premises, not due so much to the inexactitude of the author as to the imperfect data from which, I presume, his facts were collected. It is not my intention to enter into legal questions, to discuss the general evidence, or to question the decision of the jury; I propose only to record the medical history and condition of Treadaway and the professional evidence given in his defence.

On December 23rd, 1876 , I was requested by the prisoner's solicitor to investigate his mental and bodily condition, and, after five prolonged interviews with him, the following are the results of my inquiries.

Frederick Treadaway, aged 20, a Hosier's Assistant. - Family History. - According to the report handed to me by the solicitor, and to in quiries made by myself, Treadaway is the eldest of nine children. His eldest sister suffered from "brain fever" when a child; she had delirium and convulsions, and was subsequently paralysed for six months. His father is a man of depressed and melancholic temperament. His aunt died during an epileptic fit at the age of $\mathbf{2 2}$, having suffered from that disease all her life. Both his grandparents were persons of depressed and nervous habit, his grandmother being described as incompetent and requiring a companion to be constantly with her. One granduncle died imbecile, a second granduncle committed suicide, and a third granduncle died in a "fit". A grandaunt is described as a woman of "strange behaviour". His great grandmother was imbecile; one great granduncle was imbecile; and another was an inmate of St. Luke's Asylum. The daughter of a great grandaunt was an inmate of Hanwell Asylum. On the mother's side, two granduncles were insane.

Personal History. - Treadaway states that he was quite healthy till about two years ago. For twelve months prior to this, he had indulged in great sexual and alcoholic excesses. With this exception, he had before and has since led a steady and temperate life. Shortly after this, he became very subject to frequent and severe headaches of a stabbing and throbbing character, which symptom has lasted to the present time. During the last two years, he has had six or eight seizures of unconsciousness, or, as he calls them, "fainting fits". All these have been of similar character, some of them, however, being more prolonged and severe than others. He described these as follows. While in ordinary good health, without apparent cause, he suddenly experienced a severe shooting pain and throbbing in his head, followed by a giddy sensation, in which everything seemed to turn round. $\mathrm{He}$ staggered and had to lay hold of something for support. He had the sensation of a "black cloud" coming over him, and then he lost consciousness. On recovering his senses (he thinks in a few minutes), he suffered from headache and felt confused in his ideas. In a short time, the latter passed off, and he was able to walk on, and in an hour or so he was again quite well. During the last two years, and only since then, he has been subject to occasional involuntary micturition during sleep. This occurred every month or two, and without apparent cause. He has also since that time complained of various pains, sometimes in the branches of the fifth nerve, but more especially in the cardiac region, where he describes a severe pain and the sensation as if a cord was being tightly pulled round his chest. About the middle of August last, he was out of employment, and had in consequence to live at home. Although he was supported by his family, and received every kindness at their hands, he gradually became depressed and despondent. He brooded over his "misery", and finally became so melancholic (apparently without cause), that he several times contemplated "putting an end to himself" by suicide. Several methods suggested themselves to his mind, such as drowning, but he finally decided to shoot himself, as being, he thought, the most expeditious method; hence the purchase of a revolver. On the morning of December I $5^{\text {th }}$ (the day of the crime), Treadaway says he awoke with a severe headache and felt generally unwell. While sitting talking with Collins on different subjects, he experienced a sudden throbbing in his head, followed by giddiness and the sensation of a black cloud and darkness coming over him. From that moment, he remembers nothing till he found himself in the street. For the remainder of the day, he felt dazed and confused, and it was not till the following morning that he thoroughly realised his position. With the above exceptions, he has always considered himself a perfectly healthy person.

Present Condition. - Treadaway is a youth of fair complexion, somewhat short stature, well-built, and healthy looking. His forehead is low and his head small. There is nothing abnormal about his appear- 